\title{
Um réquiem pelas mulheres
}

A Requiem to Women

\author{
Paula Queiroz Dutra' (iD) 0000-0001-5533-3468
}

'Instituto Federal de Brasília, Brasília, DF, Brasil. 70830-450 - cdgp.cbra@ifb.edu.br

\section{$-1$}

MELO, Patrícia.

Mulheres empilhadas.

São Paulo: Leya, 2019.

Em seu mais recente romance, Mulheres empilhadas (2019), a escritora Patrícia Melo, sem perder o gosto pelo romance policial, decide abordar o problema persistente da violência contra as mulheres no Brasil, denunciando as diversas formas de violência presentes no cotidiano das mulheres e que têm sido mortas, diariamente, no país. São vidas não são passíveis de luto, recuperando a ideia proposta por Judith Butler em Quadros de guerra (2017) na qual algumas vidas, como a das mulheres, dos/as indígenas, dos/as negros/as, dos/as homossexuais e transexuais têm sido invisibilizadas de forma cruel, sendo-lhes negadas a chance de serem passíveis de luto pela sociedade como um todo.

Neste romance de narrador homodiegético, a protagonista é uma jovem advogada cujo passado familiar também é marcado por uma grande tragédia. Tragédia esta sublimada pela personagem como acontece com as sobreviventes de uma violência doméstica na infância e que só é relembrada em mais detalhes muito tempo depois. Buscando se afastar de um relacionamento que começa a ser abusivo, pois o namorado havia lhe dado um tapa na cara em uma festa da firma, a jovem se oferece para ir ao Acre a trabalho, com o propósito de acompanhar - como representante da empresa de advocacia em que trabalha - um mutirão de julgamentos de feminicídios ocorridos na região. De acordo com o Mapa da Violência 2019, houve um crescimento da violência letal no Acre, segunda unidade federativa com maior violência letal contra mulheres de acordo com o mesmo relatório. Com isso, a autora consegue colocar em cena a região do país onde há um dos maiores índices de violência contra a mulher. O mundo real e violento vivido por mulheres em todo o país é transposto para a ficção, mostrando que o cenário hoje para as mulheres é de um verdadeiro estado de guerra, apontando para a necessidade de um olhar mais atento e protetivo por parte do Estado, do Judiciário e da sociedade como um todo.

É nessa região que a autora, via literatura, também chama a atenção para a invisibilidade da violência contra mulheres indígenas, muitas vezes esquecidas pelo próprio movimento feminista, além de invisível aos olhos do Estado, seja pela precariedade da vida que vivem enquanto povo constantemente ameaçado de perder seu lugar no mundo, seja pelas próprias tradições que afastam as leis protetivas da realidade dessas mulheres.

O assassinato brutal de uma jovem indígena, que foi torturada e estuprada, tendo seu corpo mutilado e depois desovado por três homens da região - todos herdeiros dos seringalistas que se apropriaram das terras indígenas - causa grande indignação na jovem advogada que decide acompanhar a promotora no processo de investigação que se segue ao julgamento dos acusados. Todos foram inocentados, em um júri marcado pela corrupção. Nesse sentido, o romance de Melo aponta para as inúmeras falhas e envolvimentos de policiais e do judiciário nos processos que 
investigam as mortes das mulheres demonstrando que o sistema patriarcal também estrutura essas instituições e, por isso, ainda tem sido o responsável pela falta de punição adequada aos criminosos.

Além de trazer exemplos diversos de violências, o romance abre espaço para reflexões sobre as causas das violências contra as mulheres exercidas pelos homens, com destaque para os questionamentos acerca da pornografia como elemento importante na formação dessas masculinidades tóxicas que se constituem a partir de modelos e comportamentos violentos que passam a ser normalizados.

Cada capítulo do romance inicia com um trecho de uma notícia de jornal ou de um processo de feminicídio. Nesses trechos a realidade pulsa e denuncia o femigenocídio, nos termos de Rita Segato (2013), que temos vivido no país. Os nomes das mulheres mortas e a forma como suas vidas foram extirpadas abrem os capítulos para reforçar que o texto literário aborda um problema real que precisa ser enfrentado, que não pode ser esquecido após fecharmos as páginas do livro. Mulheres empilhadas é, portanto, um romance-denúncia que leva o/a leitor/a por essa realidade dura e violenta para as mulheres, cujas mortes nem sempre são noticiadas nos jornais. A parcialidade da imprensa nesses casos, dando destaque apenas a algumas mortes - geralmente de mulheres brancas de classe média -, e mantendo silêncio sobre as mortes de mulheres negras, pobres, indígenas e trans também é denunciada pela autora ao longo do romance, enfatizando o fato que ser passível de luto também é um privilégio.

Ao contabilizar as muitas mortes de mulheres nos julgamentos que acompanha, a advogada também registra o maior número de mulheres negras assassinadas, refletindo sobre a triste realidade brasileira que, de acordo com o Atlas da Violência 2019 (Daniel CERQUEIRA et al, 2019), apresenta um aumento expressivo da violência contra mulheres negras e uma diminuição da violência contra mulheres brancas, evidenciando a dimensão racial e de classe que não pode ser ignorada quando refletimos sobre essa violência misógina e sistêmica.

A aproximação da protagonista com os povos indígenas que habitam a região e com a própria natureza presente no local faz com que se reconecte com sua memória e sua ancestralidade. A conexão com a terra e com a floresta brota das páginas através dos sonhos vividos pela personagem durante as experiências com a ayahuasca, uma conexão feminina que recupera a ligação das mulheres com sua força original e criadora de vida, com suas antepassadas guerreiras e detentoras de grande conhecimento. Nesses sonhos, há o desejo de vingar as mortes das mulheres empilhadas em listas crescentes e de constituir um matriarcado, pois são os homens que matam, são os homens também os que destroem a natureza e os animais.

É por meio desses sonhos vividos durante o ritual xamânico que a protagonista, junto com as demais mulheres, expressa de forma violenta seu clamor por justiça pela vida de todas as que morreram. No entanto, a violência exercida por mulheres contra os homens não deve ser vista como solução para o problema global da violência de gênero. Sabendo que esse comportamento é construído, portanto, a narradora aponta para a necessidade de uma desconstrução do mesmo, como vemos no trecho a seguir:

É claro que eles não nascem, assim com desejo de matar mulheres. Alguns até nascem, os psicopatas. Mas os psicopatas são a elite dos assassinos. Já nascem prontos. A grande massa operária de assassinos, digo, a maioria, tem que aprender o ódio, antes de sair matando por aí. Meu pai aprendeu muito bem. Nada mais fácil do que aprender a odiar as mulheres. O que não falta é professor: O pai ensina. O Estado ensina. O sistema legal ensina. O mercado ensina. A cultura ensina. A propaganda ensina. Mas quem melhor ensina, segundo Bia, minha colega de escritório, é a pornografia (Patrícia MELO, 2019, p. 88).

Os sonhos são também um espaço de ressignificação da dor e de recuperação da memória da tragédia familiar então suprimida pela personagem. A vivência na aldeia e o sentimento de cuidado que a protagonista encontra ao ser tratada pela pajé da tribo quando tem malária é o que a transforma e amplia seu entendimento sobre uma existência mais pacífica, em harmonia com a natureza e livre de opressões. O romance de Patrícia Melo coloca em evidência a questão da demarcação de terras indígenas, tão urgente e importante nos dias atuais, assim como o ecofeminismo, movimento que coloca a questão ecológica e ambiental como parte do movimento feminista evidenciando que tanto as mulheres quanto a natureza têm sido exploradas, pois "o patriarcado se exprime com a mesma lógica do poder machista, opressor e totalitário da agroindústria, atacando os fundamentos da vida, na sua expressão simbólica mais profunda: a fecundidade do ser vivo" (Bárbara FLORES; Salvador TREVIZAN, 2015, p. 12).

Enquanto a investigação dos crimes ocorridos, primeiro da indígena e depois da jornalista que denunciou a corrupção do júri não é resolvida, a jovem advogada enfrenta outra forma de violência bastante comum nos dias de hoje: a violência virtual, também chamada de porn revenge, tendo suas fotos íntimas divulgadas na Internet pelo ex-namorado, que não aceita o término do relacionamento e quer se vingar. A importância de pautar o tema dos crimes virtuais, principalmente entre os/as mais jovens, serve de alerta, mas, ainda mais importante é o fato de a personagem romper o namoro na primeira agressão, mostrando o quanto a vida está em risco desde a primeira 
ocorrência de uma situação violenta. Sua decisão mostra o quão importante é romper com o ciclo de violência imediatamente. Outro ponto fundamental abordado no romance é o fato de a personagem encontrar apoio entre amigas e colegas de trabalho após a exposição de suas fotos íntimas na Internet, trazendo a reflexão sobre o efetivo sentido de sororidade, o que dá forças à advogada para usar as imagens divulgadas com a intenção de prejudicá-la para mostrar a verdadeira face de seu agressor, denunciando sua conduta criminosa em um site criado por ela.

A violência contra as mulheres está ali, no apartamento ao lado ou na nossa própria casa e a proximidade desse risco está presente em cada página da narrativa de Patrícia Melo, reverberando as estatísticas da ONU, no relatório Global and regional estimates of violence against women: Prevalence and health effects of intimate partner violence and non-partner sexual violence (Penny HOWES, 2013), de que uma em cada três mulheres sofrem violência ao longo de suas vidas. Mais que denunciar o problema, o romance traz elementos que chocam e provocam a reflexão sobre outras possibilidades de enfrentamento, sobre o novo caminho que o ecofeminismo pode representar em face ao cenário intenso de destruições que vivenciamos. Com Mulheres empilhadas, Patrícia Melo contribui de forma expressiva para romper a pouca exploração do tema da violência contra as mulheres na literatura brasileira contemporânea, como observa a pesquisa realizado por Regina Dalcastagnè (2010), enriquecendo esse olhar sobre temática tão urgente em nossa realidade com a perspectiva social feminina, como vemos no romance.

\section{Referências}

BUTLER, Judith. Quadros de guerra: quando a vida é passível de luto?. Trad. de Sérgio Lamarão e Arnaldo Marques da Cunha. Rio de Janeiro: Civilização Brasileira, 2017.

CERQUEIRA, Daniel et al (Orgs.). Atlas da Violência 2019. Brasília: Rio de Janeiro: São Paulo: Instituto de Pesquisa Econômica Aplicada; Fórum Brasileiro de Segurança Pública, 2019.

DALCASTAGNÈ, Regina. "Representações restritas: a mulher no romance brasileiro contemporâneo". In: DALCASTAGNÈ, Regina; LEAL, Virginia (Orgs.). Des/ocamentos de gênero na narrativa brasileira contemporânea. São Paulo: Editora Horizonte, 2010, p. 40-64.

FLORES, Bárbara Nascimento; TREVIZAN, Salvador Dal Pozzo. "Ecofeminismo e comunidade sustentável”. Estudos Feministas, Florianópolis, v. 23, n. 1, p. 11-34, jan.-abr. 2015.

MELO, Patrícia. Mulheres empilhadas. São Paulo: Leya, 2019.

HOWES, Penny (Ed.). Global and regional estimates of violence against women: Prevalence and health effects of intimate partner violence and non-partner sexual violence. Itália: Organização Mundial de Saúde, 2013.

SEGATO, Rita Laura. "Femigenocidio y feminicidio: una propuesta de tipificación". Labrys Estudos Feministas, Brasília, Montreal, Paris, n. 24, jul.-dez. 2013. Edição digital. Disponível em: https:// www.labrys.net.br/labrys24/feminicide/rita.htm. Acesso em: 16/11/2019.

Paula Queiroz Dutra (qpaulad@gmail.com) é Professora do Instituto Federal de Brasília (IFB) e doutora em Literatura pela Universidade de Brasília. Integra o Grupo de Estudos em Literatura Brasileira Contemporânea (GELBC) da UnB. Tem interesse em literatura contemporânea, em especial pela temática da violência sob o viés dos estudos de gênero.

\section{COMO CITAR ESSE ARTIGO DE ACORDO COM AS NORMAS DA REVISTA}

DUTRA, Paula Queiroz. "Um réquiem pelas mulheres". Revista Estudos Feministas, Florianópolis, v. 28, n. 3 , e70068, 2020.

\section{CONTRIBUIÇÃO DE AUTORIA}

Não se aplica.

FINANCIAMENTO

Não se aplica.

CONSENTIMENTO DE USO DE IMAGEM

Não se aplica. 


\section{APROVAÇÃO DE COMITÊ DE ÉTICA EM PESQUISA}

Não se aplica.

\section{CONFLITO DE INTERESSES}

Não se aplica.

LICENÇA DE USO

Este artigo está licenciado sob a Licença Creative Commons CC-BY International. Com essa licença você pode compartilhar, adaptar, criar para qualquer fim, desde que atribua a autoria da obra.

HISTÓRICO

Recebida em 16/11/2019

Aprovada em 28/02/2020 